\title{
Total Quality Management in the Malaysian Automobile Industry
}

\author{
'Ismah Osman \\ Faculty of Business Management, Universiti Teknologi MARA \\ 40450, Shah Alam, Selangor, Malaysia \\ Tel: 60-3-554-4446 E-mail: ismah817@salam.uitm.edu.my \\ Husniyati Ali \\ Faculty of Business Management, Universiti Teknologi MARA \\ 40450, Shah Alam, Selangor, Malaysia \\ Tel: 60-3-554-4446 E-mail: husni833@salam.uitm.edu.my
}

Wan Edura Wan Rashid

Faculty of Office Management and Technology, Universiti Teknologi MARA

40450, Shah Alam, Selangor, Malaysia

Tel: 60-3-5543-5549 E-mail: wan_edura@salam.uitm.edu.my

Kamauzaman Jusoff (Corresponding author)

Yale University, Yale Tropical Resources Institute, Yale's School of Forestry \& Environmental Studies, 210 Prospect St, New Haven, CT 06511, USA

Tel: 1-203-676-7761 E-mail: jusoff.kamaruzaman@yale.edu

\begin{abstract}
Due to global competition, companies have indeed emphasized that quality should have to be put in place, integrated into all aspects of products and services within their management system. Hence total quality management (TQM) has become increasingly popular as one of the managerial devices in ensuring continuous improvement as to improve customer satisfaction and retention as well as to ensure its product or service quality. Importantly, employees are regarded as the most important entity in ensuring that total quality management (TQM) can be carried out successfully in an organization. Therefore, this paper will address certain issues based on employees' perspectives with regard to TQM implementation in the SMEs of the automobile industry in Klang Valley. Specifically, the research would identify the perceptions towards TQM among the employees in the small-medium industry in the automobile sector. Secondly, to determine the important factors towards TQM implementation as perceived by those employees. Finally, to ascertain whether there are other measurements employed by the SMEs of the automobile industry in ensuring quality.
\end{abstract}

Keywords: Small-medium enterprise, Perception, Total quality management, Automobile industry

\section{Introduction}

Quality is a term that carries important meaning to both producer and customer. In the global marketplace today, many organizations realized that its survival in the business world depend highly on producing high quality product and services. Indeed, a lot of organizations have emphasized that quality should have to be put in place, integrated within the management system, especially in terms of bringing the end products or services to the customers, especially with the intense competition arriving from the rivals. Accordingly, total quality management (TQM) has become increasingly prevalent as one of the management strategies in ensuring customer satisfaction and loyalty, improving products and service quality and reinforcing continuous improvement.

This research investigates total quality management (TQM) of the small and medium scale enterprises (SMEs) in the automobile industry due to the general quest for quality-produced cars and the increasing competition between the local car producer and foreign car manufacturer. The automotive industry is chosen for the present study due to its 
importance and emphasis place in the manufacturing sector to boost the industrialization process in order for Malaysia to be a developed nation by 2020 (http://www.unescap.org, assessed on 24 April, 2007). In addition, total quality management (TQM) would be one of the measurements to ensure that the cars produced are reliable, satisfied by the consumers at large and to ensure competitiveness in the market, as well as conforming to the international standard. Therefore, the objectives of this study are three-folds, namely (i) to explore the perception of employees pertaining to the implementation of total quality management (TQM) in the automobile industry, (ii) to identify at which attribute of TQM has been chosen most by the respondents and (iii) to determine whether there are other quality measurements besides TQM that has been practiced in those respective organizations.

\section{Methodology}

This study is based on small and medium-sized enterprises (SMEs) in the Malaysian automobile industry. It is empirical as it aims to discover the perceptions of employees towards the implementation of Total Quality Management (TQM) in their organizations. Questionnaires were adopted from Zhang et al., (2000) based on 11 variables which include training, reward and recognition, product or service design, supplier quality management, employee participation, customer focus, process control and improvement, evaluation, vision and plan statement, quality system improvement and leadership. Though in terms of reliability, it has been proven valid and reliable (Zhang et al., 2000) since the questionnaires were tested and validated on 212 Chinese manufacturing companies, but yet this study also had conducted the reliability test. The reliability of the factors was determined by establishing their alpha weighting using Cronbach's alpha coefficient. Construct validity was assessed using factor analysis. The result of reliability shows that the item loading was 0.875 , thus it was concluded that the scales had good construct validity. A total of 300 questionnaires were sent to employees of the SMEs of the automobile industry in Klang Valley on a purposive sampling basis. However, only 150 employees managed to respond which gives a response rate of $43.5 \%$. Those organizations were based from Small and Medium Industries Development Corporation (SMIDEC) directory that constitute organizations that generally supply parts or provide services to the automobile industry (see Table 1). In addition to those lists, questionnaires were also sent to organizations that meet the SMEs definition, and supplying parts to Proton and Perodua or other car producer. The questionnaire basically consisted of questions to infer the employees' perception on the concept of TQM, using a five point Likert type scale, with a response of 1 indicating that respondents disagree with the item perceived and 5 indicating that respondents agree with the item perceived.

\section{Results and discussion}

\subsection{Demographic profile of respondents}

Table 2 shows the demographic profile of the respondents. A total of $52.7 \%$ of the respondents were male and $47.3 \%$ were female. In terms of the level of education, most of the respondents completed their secondary educational level (44.0\%), followed by having their first degree $(26 \%)$, diploma/certificate $(18.7 \%)$ and completed their primary education (11.3\%). The above table also shows that $34.7 \%$ of the respondents were administrative officer, executive (33.3\%), technical supervisor (28.7\%) and top management (3.3\%).

As indicated in the Table 2, 52.7\% were male and $47.3 \%$ were female. In terms of the level of education, most of the respondents completed their secondary educational level (44.0\%), followed by having their first degree $(26 \%)$, diploma/certificate (18.7\%) and completed their primary education (11.3\%). The above table also shows that $34.7 \%$ of the respondents were administrative officer, executive (33.3\%), technical supervisor $(28.7 \%)$ and top management $(3.3 \%)$.

\subsection{Understanding on the Concept of TQM by respondents}

The respondents were also being asked to indicate their general understanding on the concepts of TQM (Table 3). In generally $40.7 \%$ of the respondents associated TQM as total customer satisfaction, $34 \%$ viewed it as continuous improvement, $13.3 \%$ relates it to management leadership and commitment, while $10.7 \%$ associated it with employees' involvement. The least opinion relates TQM with training and reward (1.3\%). Eventually, the highest perception of TQM among employees relates to total customer satisfaction (4.13), followed by employee involvement, training and education (4.00), then management leadership and commitment (3.95) and finally, continuous improvement (3.82).

In order to further explore the perception of employees on the importance of TQM, a set of variables were listed to measure the degree of its important to the respondents on TQM, on a scale ranging from 1(disagree) to 5 (agree). Among the 11 variables measured based from Zhang et al. (2000) were training and education, reward and recognition, service design, quality system improvement, employee participation, customer focus, process control and improvement, evaluation, vision and plan statement, leadership, and supply quality management. Based on responses to the TQM variables, Table 4 provides mean of different employees in their perception of TQM. The result indicates that in terms of TQM variables, training and education is perceived the highest (4.09), followed by service design (4.0) and quality system improvement (3.96). The result presented in Table 4 indicates the differences of perception among the respondents on TQM variables. Since training and education shows the highest mean score (4.09), the study will 
highlights the relationship between training and education with the respondents' perception of TQM.

Table 5 illustrates the relationship between respondents' understandings on the concept of TQM with training and education. For the respondents who perceived TQM as management leadership and commitment, any follow up activities made by the management for improvement of quality job is very important (4.45). It is followed by problem solving and availability of resources for employee education and training (4.35). The least perception is on attending training program (3.95). For those who regard TQM as continuous improvement, to them employee should be regarded as the most valuable resources in ensuring the better performance of the company (4.18). They also perceived that the employees should be given greater involvement in the training program as a motivation for them to perform the job (4.12) as well as the management should made resources for employees' education and training are available (4.12). $40.7 \%$ of the respondents have associated their understanding of TQM to be total customer satisfaction. For those who regards TQM as total customer satisfaction has definitely says that the employees should be given the quality awareness education in order to ensure that the customer will satisfied with the service given (4.43). Then it followed by the importance of imparting MS ISO training awareness to the employees in order to improve their job performance (4.31). The result also shows that for those who considered employee involvement as TQM has different perception on the training variables. To them, MS ISO training awareness and greater involvement of employees in training program should be given priority (4.50). The employees also perceived that they should be exposed with a new skill on improvement of quality to reduce defective production and goods service (4.38).

The respondents were then asked on the reasons for the implementation of TQM in the organization. Table 6 shows that majority of respondents agreed that with the implementation of TQM the company would be able to increase efficiency and productivity $(53.3 \%)$, followed by the ability deliver high level of service to the customers $(17.3 \%)$, to be more competitive $(13.3 \%)$, to ensure better utilization of resources $(10.0 \%)$ and lastly, the ability to prepare for continuous improvement $(6 \%)$. The research is would also seek to identify whether there are other measurements that have been used and implemented by the organizations in terms of quality initiatives besides TQM (Table 7). The result in Table 7 shows that $52.7 \%$ are implementing TQM in managing their quality system, followed by Six Sigma $17.3 \%$. TQM is indeed, agreed upon as one of the ways of managing organizations to improve efficiency and effectiveness (Zhang et al., 2000). Nevertheless, there is not much conformity in terms of the overall view of TQM since TQM connotes different meaning to different people (Hackman and Wageman, 1995). Therefore, this study seeks to determine employees' perception on TQM since organizational performance depends highly on the performance of employees (Rodwell et.al., 2000). Furthermore, this study is conducted in the automobile industry of the small-medium enterprises (SMEs) to identify their perception on the implementation of TQM. Consequently, many researches have contributed toward the critical success factors on TQM implementation (eg., Lau and Idris, 2001; Idris, McEwan and Belavendram 1996; Dean and Helms, 1996; Thiagarajan, et al., 2001 and Behesti and Lollar, 2003). From the study, customer satisfaction is perceived the most by the employees in terms of their understanding of TQM which correspond with Bowen and Waldman (1999) argument that the most important requirement for long-term organizational success is customer satisfaction. Accordingly, customer satisfaction can only be achieved if the company continuously put an effort to improve the quality system (Robinson and Pearce, 1998). Ultimately, employees perceive their involvement as an important concept of TQM and this coincides with Dean and Helms (1996) study on the public sector agencies. In terms of the reason of implementing TQM, many of the employees perceived that organizations implement quality system mainly to increase their efficiency and productivity and this has been supported by Beshesti and Lollar (2003). Surprisingly, they neither perceive continuous improvement as one of the important component of TQM nor as the reasons for its implementation. One possible reason why continuous improvement is perceived less by the employees may due to the lack of emphasis of long-term implementation in TQM. Probably, it may also owe by the fact that some organizations implement TQM in order to gain ISO certification or other quality certification. Importantly, training and education, followed by service/product design and quality system improvement are regarded as the most important factors perceived by employees among the 11 dimensions of critical success factors of TQM implementation in the automobile industry of the SMEs. The findings however did not support Eng and Yusoff (2003) study where they mentioned that training and education for the implementation of TQM practices tend to be successful only in large companies compared to SMEs. The other factors that are perceived important are service/product design and quality system improvement and this has been supported by Thiagarajan, et al. (2001) who also did a study on TQM implementation in Malaysia.

\section{Conclusion}

Even this study presents a general framework for advancing the knowledge and perception of the employees on TQM, it may help the automobile industry to improve their service to the customer. In fact, quality control is much required in small firms as to emulate the big companies as well as to match the quality to differentiate their product or services from their competitors. Furthermore, TQM will give an impact towards significant returns, performance improvements, better teamwork and decision in services. 


\section{References}

Behesti, H. M., and Lollar, J. G. (2003). “An empirical study of US SMEs using TQM". TQM and Business Excellence, 14(8), 839-847.

Bowen, D. E., and Waldman, D. A. (1999). "Customer-driven employee performance". In Ilgen, D.A. and Pulakos E.D. (ed), The changing nature of performance, 154-191, San Francisco, Jossey-Bass.

Dean, M. B., and Helms, M. M. (1996). "The implementation of total quality management into public sector agencies: a case study of the Tennessee Valley Authority". Benchmarking for Quality Management and Technology, 3(1),

pp. $50-64$.

Eng. Q. E., and Yusoff S. M. (2003). “A survey of TQM practices in the Malaysian electrical and electronic industry”. Total Quality Management, 14(1), pp. 63-77.

Idris, M. A. , McEwan, W., and Belavendram, N. (1996). "The adoption of ISO 9000 and total quality management in Malaysia”. The TQM Magazine, 8(5), pp 65-68.

Lau, H. C., and Idris, M. A. (2001). "The soft foundation of the critical success factors on TQM implementation in Malaysia”. The TQM Magazine, 13(1), pp. 51-60.

Robinson, R. B. Jr., and Pearce, J. II (1998). "Planned patterns of strategic behaviour and their relationship to business-unit performance". Strategic Management Journal, 9, 43-60.

Thiagaran, T., Zairi, M., and Dale, G. B. (2001). "A proposed model of TQM implementation based on an empirical study of Malaysian industry". International Journal of Quality and Reliability Management, 18(3), pp. $289-306$.

Zhang, Z., Waszink, A., and Wijngaard, J. (2000). “An instrument for measuring TQM implementation for Chinese manufacturing companies". International Journal of Quality and Reliability Management, 17(7), 730-755.

Zhang, Z. (2000). "Developing a model of quality management methods and evaluating their effects on business performance". Total Quality Management, 11(1), pp. 129-37.

http://www.unescap.org accessed on 24 May, 2007.

Table 1. Definition of SMEs by Small and Medium Industries Development Corporation (SMIDEC) by Size

\begin{tabular}{|c|c|c|c|}
\hline Category & Micro-Enterprise & Small Enterprise & Medium Enterprise \\
\hline $\begin{array}{l}\text { Manufacturing, } \\
\text { Manufacturing-Relat } \\
\text { ed Services and } \\
\text { Agro-based } \\
\text { industries }\end{array}$ & $\begin{array}{l}\text { Sales turnover of less than } \\
\text { RM250,000 OR full time } \\
\text { employess less than } 5\end{array}$ & $\begin{array}{l}\text { Sales turnover } \\
\text { between RM250,000 } \\
\text { and less than RM10 } \\
\text { million OR full time } \\
\text { employees between } \\
5 \text { and } 50\end{array}$ & $\begin{array}{l}\text { Sales turnover between } \\
\text { RM10 million and } \\
\text { RM25 million OR full } \\
\text { time employees } \\
\text { between } 51 \text { and } 150\end{array}$ \\
\hline $\begin{array}{l}\text { Services, Primary } \\
\text { Agriculture and } \\
\text { Information } \quad \& \\
\text { Communication } \\
\text { Technology (ICT) }\end{array}$ & $\begin{array}{l}\text { Sales turnover of less than } \\
\text { RM200,000 OR full time } \\
\text { employees less than } 5\end{array}$ & $\begin{array}{l}\text { Sales turnover } \\
\text { between RM200,000 } \\
\text { and less than RM1 } \\
\text { million OR full time } \\
\text { employees between } \\
5 \text { and } 19\end{array}$ & $\begin{array}{l}\text { Sales turnover between } \\
\text { RM1 million and RM5 } \\
\text { million OR full time } \\
\text { employees between } 20 \\
\text { and } 50\end{array}$ \\
\hline
\end{tabular}

(source: Small and Medium Industries Development Corporation (SMIDEC) 
Table 2. Respondents Demographic Profile

\begin{tabular}{lll}
\hline Variables & $\%$ & $\mathrm{~N}$ \\
\hline Gender & & \\
Male & 52.7 & 79 \\
Female & 47.3 & 71
\end{tabular}

\section{Ethnic Group}

Malay

$77.3 \quad 116$

Chinese

9.3

14

Indian

7.3

Others

6.0

9

Years of working

Less than one year

$9.3 \quad 14$

5-10 yrs

$21.3 \quad 32$

$1-5 \mathrm{yrs}$

49.3

Over 10 yrs

20.0

Job status

Technical Supervisor

28.7

43

Executive

33.3

50

Administrative Officer

34.7

52

Top Mgt

3.3

5

Education level

Primary and Below

$11.3 \quad 17$

Secondary

$44.0 \quad 66$

College

$18.7 \quad 28$

University

26.0

Income

Less than RM 1000

19.3

29

RM3001-RM5000

21.3

32

RM1001-RM3000

55.3

83

More than RM 5000

4.0

6 
Table 3. Respondents' Understanding on the Concept of TQM

\begin{tabular}{llll}
\hline Items & Percentage & Mean & Frequency \\
\hline Management leadership & 13.3 & 3.95 & 20 \\
and commitment & & & \\
Continuous improvement & 34.0 & 3.82 & 51 \\
Total customer satisfaction & 40.7 & 4.13 & 61 \\
Employee involvement & 10.7 & 4.00 & 16 \\
Training and education & 1.3 & 4.00 & 2 \\
\hline
\end{tabular}

Table 4. Mean for TQM variables

\begin{tabular}{ll}
\hline TQM variables & Mean \\
\hline Training and education & 4.09 \\
Reward and recognition & 3.81 \\
Service/product design & 4.00 \\
Quality system improvement & 3.96 \\
Employee participation & 3.75 \\
Customer focus & 3.95 \\
Process control and improvement & 3.74 \\
Evaluation & 3.94 \\
Vision and plan statement & 3.92 \\
Leadership & 3.70 \\
Supply quality management & 3.47 \\
\hline
\end{tabular}

Table 5. Understandings on the Concept of TQM and Training by Respondents

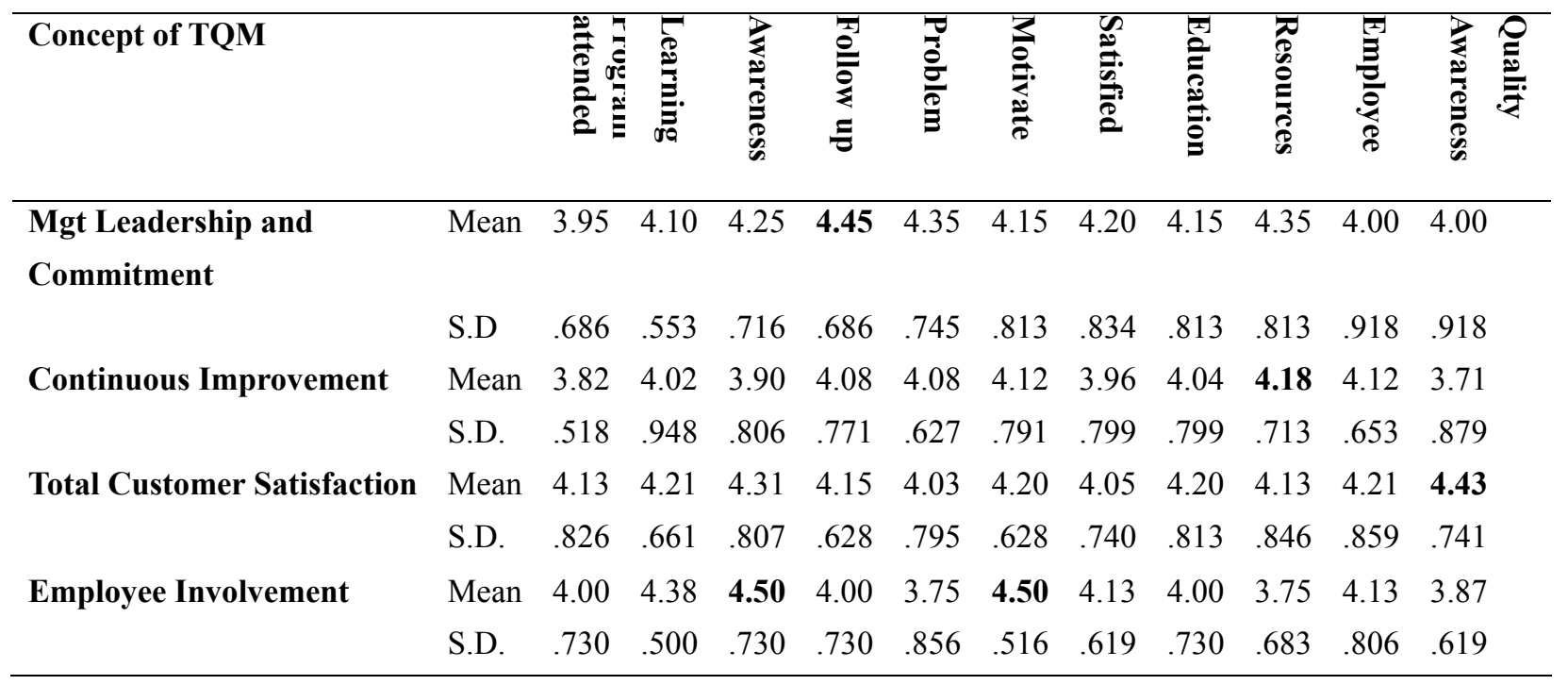


Table 6. Perceptions of Employees on the Importance of TQM Implementation

\begin{tabular}{lll}
\hline Items & $\%$ & $\mathbf{N}$ \\
\hline To be competitive & 13.3 & 20 \\
To increase efficiency and productivity & 53.3 & 80 \\
Better utilization of resources & 10.0 & 15 \\
For a high level of service to the customers & 17.3 & 26 \\
For continuous improvement & 6.0 & 9 \\
\hline
\end{tabular}

Table 7. Other Measurements Employed by SME

\begin{tabular}{|l|l|l|}
\hline Measurements & $\mathbf{\%}$ & N \\
\hline Six Sigma & 17.3 & 26 \\
\hline Balance Scorecard & 14.0 & 21 \\
\hline Total Quality Mgt & 52.7 & 79 \\
\hline Others & 16.0 & 24 \\
\hline Total & 100.0 & 150 \\
\hline
\end{tabular}

